\title{
E-LEARNING IN ENTERPRISE: CHALLENGES FOR INTRODUCTION
}

\author{
Deniss Ščeulovs ${ }^{1}$, Elīna Gaile-Sarkane ${ }^{2}$ \\ ${ }^{I}$ Riga Technical University, Latvia, deniss.sceulovs@rtu.lv \\ ${ }^{2}$ Riga Technical University, Latvia, elina.gaile-sarkane@rtu.lv \\ cross'ref http://dx.doi.org/10.5755/j01.em.17.1.2281
}

\begin{abstract}
David Starr Jordan said: "The world stands aside to let anyone pass who knows where he is going". The same principle stands for companies - a company that can change in a highly competitive environment and in the current economic situation will be able to maintain its competitiveness. Nowadays, the only way how to be successful is to be able to adapt to constantly changing internal and external business environment conditions and to oversee and find original solutions to significant business issues and challenges. One of the most modern tools that help companies develop their business is an e-learning.

Among specialists, there is no common understanding about e-learning and there are very different views on the "e-learning" concept and importance. An analysis performed by the authors, dealing with the forms of e-learning at organizations, showed that a computer is not always used in the implementation of elearning (the authors of the paper consider that the concept of a computer is too narrow and in reality does not reflect the current situation of e-learning). As a result of analyzing, evaluating, and combining various definitions of e-learning that are provided in different sources, the authors have created their own definition of e-learning: e-learning nowadays is the process of personnel training and skill development on the basis of modern information and communication technologies, providing the trainees with the simultaneous audio, visual and interactive stimuli.

Keywords: e-learning, IT, enterprise, factors.

JEL Classification: A20, L21, L26, M20.
\end{abstract}

\section{Introduction}

E-learning dates back to the 50 -ties of the $20^{\text {th }}$ century. R. Meier considers that the first steps in elearning development were taken already back in 1950-ties, when the Stanford University in collaboration with IBM created a very simple training programme for elementary school students. This study programme was based on a principle "question - answer - evaluation - next question" and its technical base was a mainframe computer. F. Keller for the first time created a learning system, modern for the time, to be used in military training, and it was based on a principle "learning objective - instructions - final test". During the 1970-ties, the society increasingly voiced a belief that the electronic training form features nearly inexhaustible opportunities, however due to the limited technical possibilities of those times; the prepared training programmes were mostly intended for specialists working on mainframe computers. The situation changed radically during the 1980-ties, when computers available for the general public were introduced. Since these pioneering computers did not feature high quality graphics, the training programmes of that time did not differ much from the book, the pages of which were turned by the computer (Meier, 2006).

In a report prepared by Brandon Hall Group covering development of e-learning systems on a global level, four phases of e-learning system development were distinguished. The first phase 1980-1990 Training Registration Systems (support, classrooms, training) (Meier, 2006). The second phase 1990-2000 Course Management Systems (support, CD-based learning). The third phase 2000-2010 Learning Management Systems (support, online learning). The fourth phase 2011-now - Wide Range of Learning Management Systems (support, learning and talent) (Nantel, 2011). Several authors express the same view that the next great opportunity for e-learning development was ensured by Internet (E-learning, 2011), and the authors of this paper agree with this opinion.

Objective of the paper: to describe and evaluate the e-learning idea and concept, to determine which factors influences a company e-learning activities. To conduct a study about training processes at companies, to analyse and conclude, whether e-learning can replace certain training possibilities in a company, what are the advantages and disadvantages?

Research methodology: the authors employ well-established quantitative and qualitative methods of research: grouping, analysis, statistic method, etc.

Theoretical and methodological background of the research is formed of scientific researches and publications, publications from mass media and professional literature; statistical information from legal institutions as well as information collected by the author during the survey. 
Originality/value. In this paper the authors presented their findings based on theoretical, scientific and field research. Authors have conducted research on e-learning utilization among Latvian enterprises.

\section{E-learning Trends in the World and Latvia}

In order to evaluate the global trends of e-learning, the authors used the study performed by Towards Maturity dealing with trends of using modern technologies at work place for 2011-2012. Studies of this type have been conducted for 8 years already; in 2011, 767 respondents - companies from across the world participated in the study. The study provides a broader multi-perspective outlook on the use of modern technologies in personnel training and development, as well as gives information about the trends in the sphere for 2012 (Towards Maturity, 2011). Out of the overall data of the study, the authors of the paper focus on the trends of types of training used in e-learning at organisations.

According to the study, the most popular e-learning forms are e-courses, online training events and learning platforms. Various types of e-courses are implemented in $80 \%$ of respondent organisations. $77 \%$ of respondents use study forms online - online seminars, conferences etc. $71 \%$ of respondents use learning platforms, where questions can be asked and answers can be received to these questions. The study data show that the majority of organisations, where e-learning is used as one of the staff training methods, 30$40 \%$ out of the overall training volume is rendered through e-learning. The study also included respondents, who indicated that staff training is organised fully in a form of e-learning.

The authors of the paper consider that the extent of overall training in an organisation that can be organised in a form of e-learning depends on the specifics of the company and on the type of entrepreneurship.

To analyse the attitude of Latvian enterprises towards e-learning, the authors of the work used a 2010 study conducted by the Latvian Association of Business Consultants and Latvian Association of Personnel Management "Role and topical tasks of personnel management in an organisation", and in particular the part dealing with e-learning. 141 respondents participated in the survey, the survey period spanned from 1423 December 2011. The study considered the personnel training measures planned in organisations. $45 \%$ of enterprises having a human resources department (a human resources specialist) planned to employ elearning in training personnel in 2010. $49 \%$ of companies, which do not have a human resources department or a human resources specialist, planned to employ e-learning in staff training in 2010. The authors of the paper draw the attention to the fact that enterprises, which do not have a human resources department or a specialist, employ e-learning more. The authors explain this situation with the fact that organisations are aware of the need of training, as well as of the opportunities to perform training using smaller financial and time resources.

\section{E-learning Overview}

There are many forms of e-learning, as described by specialists. The authors of the paper group elearning forms in seven key groups as follows:

1. E-learning forms on data carriers;

2. Internet-supported e-learning forms;

3. Cooperative learning forms;

4. Mobile learning forms;

5. Learning forms through games;

6. Social learning forms;

7. Mixed learning forms.

E-learning forms on data carriers. The learning material is stored on information carriers - such as CD and DVD (E-learning, 2011), as well as USB memory cards. These e-learning forms are implemented without the intermediation of Internet (Moriz, 2008). This type of learning form is mostly used for unassisted learning, in which the ability of the learning participant to study unassisted and be self-disciplined is of great importance. This type of e-learning is used ever more rarely, because this type of learning programmes cannot be supplemented and updated (Dublin, 2011).

Internet-supported e-learning forms. The learning material is not placed locally on a data carrier, but instead is available via internet or intranet on a server. To access the learning material, login is required. Information volume also in this case is fixed, i.e. the study course includes a set number of sections, lectures, or exercises. The advantage of this form of training - there is an option to communicate online with the person in charge of learning, other users (E-learning, 2011; Dublin, 2011). The study material, which is 
placed on the server, can be easily updated, therefore an opportunity is ensured to quickly introduce changes in the study material, in order for it to be suitable for the current needs of the organisation. The learning process employs learning platforms, the execution and quality of which can vary greatly; popular learning management systems include moodle, Blackboard, Sakai, Digitec, Meridian among others.

The authors are of the opinion that this form of e-learning undoubtedly is effective, insofar as the aspect of interactivity of the platform contents is taken into consideration, which for its part increases the costs for preparing the study content; likewise, the platforms require certain investments, as well.

In cooperative learning forms, duration of the study course is not restricted with volume and structure of study materials prepared and structured in advance. Instead, at the beginning of learning, the users agree on the progress and duration of a course or seminar. Cooperation and communication with the rest of the learning participants is named as the key feature, besides acquiring the study material. This type of learning forms is defined as the best alternative to a face-to-face conversation (E-learning, 2011). Cooperative learning forms include video-conferences, virtual seminars or webinars, virtual learning centres, which can offer learning for an unlimited number of learning participants, besides, the learning, is not linked to a particular venue. Owing to the possibility of simultaneous support provision to learning participants, questions that the learning participants might have during the learning process can be answered right away and they can be included for more effective acquisition of the study material. As the opinion voiced by W. Moriz goes, it is exactly this simultaneous learning form that to the greatest extent resembles the traditional learning process, only presented in digital format. (Moriz, 2008).

Special platforms are also prepared for organising video-conferences and webinars providing such functions as showing the study material to the participants, while commenting and making notes in the displayed slides; the study material can be supplemented with animations, video, 3D objects, as well as using a web camera, to establish eye contact with study participants, etc., questions can be asked, and answers to these questions can be given right away both in writing and orally, study materials can be spontaneously added, if questions have arisen, within the framework of a webinar platform, it is possible to divide the total number of study participants into smaller work groups, the webinar can be led simultaneously by several learning supervisors, already during a webinar, it is possible to check the comprehension of the study material; there is an option to obtain automatically feedback on webinar quality and its usefulness, as well as successful solutions are proposed for registering for a webinar, sending reminders, recording webinars, as well as mostly a module is integrated in platforms, where the learning participant or somebody, who could not participate at the webinar, can watch the webinar again at a later time (WebEx, 2011).

There are many webinar platform providers available on the market, such as, Adobe Systems GmbH, Citrix Systems GmbH, WebEx Communications Deutschland GmbH, among others (Musekapm, 2010). The authors believe that webinars can be considered as an effective substitute for seminars attended in person and reckon that the greatest advantage of these study forms is the fact that training is practically carried out in a form of a dialogue. Platforms intended for this purpose can also be rented, thus reducing costs.

Mobile learning forms are all "wireless" learning forms. Nowadays, this opportunity is provided by laptops and smartphones (Dublin, 2011). As expressed by German personnel management experts, and the authors concur with this opinion, - the use of these learning forms is facilitated by the fact that, in our day, devices of this type are our daily companions (Breitner, 2011). Moreover, it is exactly this form of learning that in comparison with the traditional learning forms most successfully support a new learning phenomenon, which has already earned recognition among professionals in Europe - micro-learning, the essence of which is learning, using smaller volume of study materials by means of the study contents. Micro-learning thus provides step-by-step learning on a daily basis (Breitner, 2011).

The authors consider that the greatest advantage of these learning forms is the possibility of learning anywhere, while the second advantage is particularly the use of micro-learning - acquiring minor amounts of information over a short time period.

Learning forms through games - these are digital games with serious study contents, the game takes places in virtual environment. Games of this type are used to simulate and model issues related to entrepreneurship. During a game, the participants must make decisions on how to act, they experience the consequences of their decision, they learn from mistakes, learn to understand other participants of the game. A well-created game prepares the study participants for everyday situations, they require complex thinking and are enjoyable to acquire. (Dublin, 2011; Goertz, 2011).

Social learning forms are all digital media and instruments, with the assistance of which the users can learn together - by exchanging information, the necessary materials, preparing joint projects. This type of 
media includes social networks, wikis, blogs. For instance, the data bank Technorati lists more than 1.2 million blogs, of which about 20000 relate to the working life. (Stehr, 2010). These study forms are referred to as social study forms, because the uniting elements for the learning are people instead of the study material (Dublin, 2011). The most popular media supporting social study forms are Facebook, LinkedIn, MySpace, Twitter, YouTube. It includes also virtual worlds, for instance, Second Life, moreover, it is emphasised that various media can be effectively used at the same time, because they feature differing business models, accordingly, options offered by Facebook are not offered by LinkedIn (Using Social Media, 2011). One of the mentioned positive side-effects for learning organised this way is the condition that cooperation relationship established during the learning process between the learning participants is for the most part continued also as cooperation after the learning is complete, i.e. foundation is laid for further work cooperation (Lake, 2011). This form of learning can be unsecure from the perspective that any action online leaves trace (cookies), therefore attention must be paid to the security aspect to avoid information leak (Dublin, 2011).

Mixed learning forms are e-learning forms with learning in presence, i.e. both learning forms support and supplement each other. An ever increasing number of proponents for this learning form were observed when it became clear that e-learning supplemented by learning in presence, fosters motivation of study participants to take more active part in the study process (Dublin, 2011). The authors reckon that synergy of both types of learning occurs in this case, i.e. the best is taken from each type of learning - from e-learning it is the option to study independently of place or time, studying at own pace. However, during the learning sessions attended in person, the learning participants can exchange opinions among them and ask the teaching person about the unclear issues. This type of learning is used when practical skills must be acquired besides theoretical knowledge (Dublin, 2011).

R. Meier expresses an opinion that overall e-learning is not more effective than learning in presence; it all depends on the measures for improving professional qualifications, on the objectives, and on the conditions under which they are implemented (Meier, 2006). The authors concur with this opinion and would like to emphasise that effectiveness of e-learning in an organisation depends on the first step following implementation of e-learning. How the e-learning processes would be planned, managed, and administered on a daily basis.

\section{E-learning implementation process}

The authors consider that the entire process of e-learning implementation can be divided into three stages: evaluation of affecting factors restricting e-learning, choice of the e-learning medium, development and fulfilment of an e-learning implementation plan.

\section{Evaluation of factors affecting e-learning}

1. Factors affecting the objectives of e-learning.

The authors believe that, upon introducing e-learning in an organisation, it is necessary to evaluate the objectives and fields, in which e-learning is expected to be used: vocational, qualification training; computer training; language learning, or behaviour-, action-oriented learning - this field of learning can be distinguished more specifically - method and social competence learning fields. The method competences refer to knowledge, skills, and abilities in fields like time management, project management, presenting technique, rhetoric. Social competences - knowledge, skills, and abilities with respect to communication with other people, e.g., management, employee motivation, conflict resolution (Meier, 2006).

It is not a mandatory condition to use only e-learning in all fields. Thus, for instance, in implementation of vocational, qualification learning, as well as computer training, e-learning is considered as very suitable. When assessing implementation of e-learning for language acquisition, the language learning components must be analysed, because self-instruction and conversation are incompatible concepts, i.e. not one, even well-developed language learning computer programme, can replace a human dialogue, however it is believed that e-learning is suitable for acquiring new vocabulary and grammar, likewise, high professional level programs can offer adequate support in pronunciation acquisition. Speaking of behaviour-oriented learning, according to e-learning experts, nearly all learning therein can be easily divided into knowledge acquisition, practicing the acquired behaviour, and exchanging opinions, experience with others. The dominating opinion is that in acquisition of both the methods and social competences, there will always be a part of the study process, which will consist of theoretical knowledge. This knowledge can be acquired by studying independently, and then by trying out the theoretically acquired knowledge and applying it in daily work (Meier, 2006). 
To sum up, the authors conclude that when evaluating the learning forms topical for the enterprise, a decision must be made concerning the fields that are suitable for employing e-learning.

2. Factors affecting the form of e-learning.

The factors that are important for the organisation itself, e.g., the number of employees to be trained, their location, whether they are constantly at their work place or not, whether training should proceed stepby-step, or according to the principle "just in time", i.e. training is carried out when the particular knowledge is necessary (Meier, 2006) among others. Moreover, the authors believe that an enterprise must assess such factors as the interest expressed by employees in using new learning forms, the current technical and financial possibilities of the organisation in implementing e-learning, whether the employees are sufficiently savvy in modern technology use, etc.

3. Factors affecting the learning topic and its priority level.

R. Meier recommends that when determining the learning topics an analysis should be performed regarding the type of training carried out for a large number of employees up to that point in time on a regular basis, several times per year, the topics, which need to be "refreshed" from time to time, the topics that are expected to be relevant in future periods, while assessing the topics, which, when acquired by the staff, cause regular, considerable costs, the topics, the learning of which takes longer than 3 days, which qualification measures consist of single seminars, or which qualification measures could be divided into separate seminars? According to the determined topics, the learning target groups are defined (Meier, 2006).

The authors recommend determining the topics, which could be acquired with pre-determined elearning forms and the target groups of these topics.

\section{Choice of e-learning medium}

When choosing the medium to be used in e-learning, the method of supporting the learning process must be determined: whether it will be a system based on using a computer or another medium.

E-learning experts, when making a decision on the most suitable medium, suggest evaluating the following suitability of medium: for the selected target groups, the set objectives and content, the level of preliminary knowledge of the trainees, the company's functions, suitability of medium for applicability requirements, costs, etc.

\section{Development and implementation of an e-learning plan}

The authors recommend using project management elements, when implementing e-learning in a company. It helps the implementers of e-learning to understand the sequence of actions to be taken, as well as to envisage the possible complications and eliminate errors in a timely manner. The e-learning plan should contain:

1. objectives for implementing e-learning;

2. sequence of key activities;

3. participants of implementing the plan and their tasks;

4. tasks to be performed within the framework of selected activities;

5. deadlines (Meier, 2006).

The authors agree with the opinion voiced by e-learning experts that after implementing e-learning, considerable attention must be paid to communication. The learning participants must give an evaluation of learning, express their opinion. Employees must be informed about "success stories", inform about the most active learning participants, etc. (Born, 2010; Dublin, 2011).

The authors believe that management of the e-learning process could be fostered by the use of technology adaptation models, which would help determining, how fast e-learning can be implemented and which fields can be implemented? Which employees can be first to be engaged in the e-learning process and which ones must be prepared, among other things. Thus, for instance, the Innovation Adaptation Model by Everett M. Rogers can be used (Digitāla biznesa rokasgrāmata, 2011). The authors consider that this model can be used in determining the body of trainees to participate in the e-learning process. The model has been adapted to the high technology marketing by Dr Geoffrey Alexander Moore, who considers that in order for an idea based on innovative or modern technologies to be viable, each adaptation group must be recognised, its relations with the neighbour must be understood, and individual discussions must be carried out (Moore, 1991).

Davis Technology Acceptance Model (Davis, 1989) predicts information technology acceptance and usage. In this model the user's behavioural intention to use a technology is affected by their perceived usefulness and perceived ease of use of the technology. This model was originally developed for studying 
technology at work. Later it has been used as such or modified to study user acceptance of consumer services such as Internet services or e-commerce (Kaasinen, 2005). The Technology Acceptance Model constitutes a solid framework for identifying issues that may affect user acceptance of technical solutions. As Davis and Venkatesh (Venkatesh et al. 2003) have proved, the model can be enhanced from the original purpose of studying user acceptance of existing products to study planned product concepts, e.g. in the form of mockups. This indicates that Technology Acceptance Model could also be used in connection with technology development projects and processes to assess the usefulness of proposed solutions. Applied in this way, the model also supports the human-centred design approach. Innovation Diffusion Theory a widely supported model used in a variety of fields identifies five factors that impact technology adoption (Moore, Benbasat, 1991): compatibility, complexity, observability, relative advantage, trialability. According to these factors seven constructs for individual acceptance of technology were developed: compatibility, ease of use, image, relative advantage, results demonstrability, visibility, and voluntariness of use. The authors believe that these factors can be used in evaluating and selecting the e-learning project. It will facilitate the evaluation of project sustainability and of how quickly and successfully it will be implemented and developed.

\section{A Study: The Opinion of Latvian Enterprises about Implementing E-Learning}

To verify the need of e-learning implementation, the authors have performed a survey of owners and employees of micro-enterprises. The aim of survey was to determine the opinion of enterprises about elearning and the opportunity to implement it in certain fields or completely replace traditional training forms with it. Research period: November-December 2011. The respondent group included owners of 32 enterprises, respondents - top managers and department directors, both gender, age group 30-67. The survey questionnaire included 10 questions, incl., and 2 open-ended questions.

Study results:

$19 \%$ of respondents believe that their respective company carries out sufficient amount of training, $50 \%$ of respondents - nearly sufficient amount, $28 \%$ consider that training is not implemented sufficiently, and $3 \%$ - training is absolutely insufficient.

In companies of $47 \%$ of respondents' employees feel comfortable using modern technologies, $44 \%-$ very comfortable, while $6 \%$ do not feel particularly comfortable using modern technologies, and $3 \%$ avoid using modern technologies, if possible.

$60 \%$ of the total number of respondents acquires new learning material best in real activities, i.e. by doing. $31 \%$ of the total number of respondents acquires the learning material effectively by discussing it, talking it over, exchanging opinions. However, $6 \%$ of the surveyed respondents acquire the learning material by watching, and only $3 \%$ - by listening. Moreover, respondents voiced an opinion that a comprehensive learning process in various proportions requires all of the offered learning options. The authors note that at the time of making a decision on the desirable e-learning form, insofar as it is possible, a combination of all types of learning should be chosen, because the more comprehensive is the combination, the more effective and successful is the performed training.

The level of awareness of respondents regarding the forms of e-learning: $32 \%$ are informed about forums and blogs, $2 \%$ - learning in social online networks, $4 \%$ - learning through games, learning in a cell phone $-5 \%$, video conferences and webinars $-22 \%$, learning platforms $-9 \%$, and learning programmes in CD and DVD carriers $-29 \%$.

What learning and in which fields can be carried out electronically? $16 \%$ of respondents indicated acquisition of behavioural/action knowledge, $12 \%$ - language knowledge acquisition, $9 \%$ - acquisition of computer program knowledge, $32 \%$ - acquisition of trade-specific knowledge.

To sum up, the authors believe that overall the attitude among the entrepreneurs is rather positive towards e-learning. They gladly would use e-learning in their enterprises, by replacing or combining it with traditional learning types. At the same time, they lack more detailed information about the e-learning types, possibilities, and costs.

\section{Conclusions}

E-learning in the modern-day understanding is a learning process based on modern information and communications technologies, providing the learning participant with simultaneous visual, audial, and interactive stimuli. 
The most significant advantages of e-learning - reduced learning costs, time savings. The most significant disadvantage - e-learning is not suitable for satisfying all learning needs, it is not suitable for all learning target groups.

Before implementing the final version of e-learning medium, the organisation should implement the socalled pilot project, which is one of the tools of avoiding mistakes when making the final decision, as well as allowing changes in implementing the final version of a medium.

Webinars are the most similar type of learning form resembling a dialogue in seminars attended in person. Besides, the webinar platforms allow improving and expanding the seminar content, as well as ensuring expert attraction. The webinar platforms enable, firstly, increasing the number of regular learning, secondly, the number of trainees.

\section{References}

1. Bieten Sie kostengünstig ein anregendes Schulungserlebnis mit Cisco WebEx Training Center Online Classroom / WebEx Communications GmbH, c/o Cisco Systems GmbH. http://de.wbximg.com/includes/documents/datasheets/tc_ds_de.pdf. (19.11.2011).

2. Boosting Business Agility: Towards Maturity (2011-12) Benchmark / Towards Maturity. http://www.towardsmaturity.org/article/2011/05/27/towards-maturity-2011-benchmark-study (20.12.2011.)

3. Born, J. Das (2010). eLearning - Praxisbuch: Online unterstützte Lernangebote in Aus-und Fortbildung konzipieren und begleiten: Ein Hand- und Arbeitsbuch.- Baltmannsweiler: Schneider Verlag Hohengehren GmbH, 2010. -251 .

4. Breitner, H.. Microlearning in der berufsbegleitenden Fort- und Weiterbildung: Mit Wissenshäppchen zum Lernen verführen//Personalführung. (2011), 40 - 48.

5. Davis, F.D. (1989). Perceived Usefulness, Perceived Ease of Use, and User Acceptance of Information Technology, MIS Quarterly 13 (3), 319-340.

6. Digitāla biznesa rokasgrāmata. http://rokasgramata.lv/vadiba/izgudrojuma-\%e2\%80\%93-inovacijas-\%e2\%80\%93izkliedesanas-triade/ (24.01.2012).

7. Dublin, L. Moving From the Classroom to Online Learning: Critical Success Factors / Dublin Consulting. http://www.webex.com/webinars/Moving-From-the-Classroom-to-Online-Learning-Critical-Success-Factors (12.11.2011)

8. Elearning: Ideen, Begriffe, Infos, ein Leitfaden zur Orientierung / Kammer für Arbeiter und Angestellte für Wien. http://wien.arbeiterkammer.at/bilder/importiert/elearning_leitfaden.pdf (01.11.2011)

9. Goertz, L. Einsatzmöglichkeiten für Serious Games in Unternehmen: Spielerisch lernen und Zusammenhänge erkunden// Personalführung. (02/2011), 58 - 65.

10. How to Promote the Value of Online Training Within Your Organization/Training Industie, Inc. and Citrix Systems,Inc.http://www.gotomeeting.com/fec/images/pdf/GoToMeeting_TrainingIndustry_OnlineTrainingROI.pdf (23.12.2011).

11. Kaasinen, E. (2005). User acceptance of mobile services-value, ease of use, trust and ease of adoption. http://www.vtt.fi/inf/pdf/publications/2005/P566.pdf (23.10.2008)

12. Lake, S. Today's Innovations, Tomorrows Trends: Learning Technology that is Supporting Improved Performance BrandonHall Group. https://www3.gotomeeting.com/en_US/island/webinar/ registration Post.tmpl?Action=rgoto\&_sf=2 (12.12.2011).

13. Meier, R. (2006). Praxis E-Learning: Grundlagen, Didaktik, Rahmenanalyse, Medienauswahl, Qualifizierungskonzept, Betreuungskonzept, Einführungsstrategie, Erfolgssicherung. - Offenbach: GABAL Verlag $\mathrm{GmbH}$.

14. Moriz, W. (2008). Blended - Learning: Entwicklung, Gestaltung, Betreuung und Evaluation von ELearningunterstütztem Unterricht. - Norderstedt: Books on Demand GmbH, 101 p.

15. Moore, G. "Crossing the Chasm" (1991). Capstone Publishing Limited 1999, 213 p.

16. Moore, G., and Benbasat, I. (1991). Development of an Instrument to Measure the Perceptions of Adopting an Information.

17. Musekamp, C. (2010). Webinare für Einsteiger: Online Seminare lebendig gestalten/C. Musekamp, D.Staemmler. Hamburg: Infoport GbR, 2010. - 107 p.

18. Nantel, R. How to Select an LMS for Your Small/Medium Business / BrandonHall Group. https://www3.gotomeeting.com/en_US/island/webinar/registrationPost.tmpl?Action=rgoto\&_sf=2 (17.11.2011).

19. Stehr, C. (12/2010). Blogs rund um das HR-Management: Geschwätzig, informativ und hemmungslos werblich// Personalführung. $18-22$.

20. Using Social Media to Advance Your Online Training Program: eGuide / Quantum Leap Marketing. http://www.gotomeeting.com/fec/images/pdf/GoToTraining_QLM_Social_Media_in_Learning.pdf (23.11.2011).

21. Venkatesh V, Morris M, Davis G, and Davis F. (2003). "User Acceptance of Information Technology: Toward a Unified View", MIS Quarterly, 27 (3), 425-478 